\title{
Effectiveness of reducing seismic hazard by means of group winning blasting - case study from a copper ore mine in Poland
}

\author{
Anna Barbara Gogolewska ${ }^{1,{ }^{*}}$, and Natalia Czajkowska ${ }^{2}$ \\ ${ }^{1}$ Wrocław University of Science and Technology, Wrocław, Poland \\ ${ }^{2}$ Graduate from Wrocław University of Science and Technology, Wrocław, Poland
}

\begin{abstract}
The copper ore deposit situated in the south-west of Poland is mined by three underground mines owned by KGHM Polish Copper JSC. Exploitation has been accompanied by rock burst hazard since the beginning. Thus, numerous different preventing measures have been developed such as temporary, organizational and long-term ones. However, no one has been able to predict the time, place and energy of a seismic event. The group winning blasting, with maximum number of blasted faces, is the most effective operation to reduce seismic threat. The more faces are blasted the more seismic energy should be reduced. The study aims at assessing the blasting effectiveness in inducing rock bursts and tremors. For this purpose, the seismic activity induced by mining and blasting were investigated. The number of blasting works and blasted faces as well as length of time between subsequent blasting works were analysed and related to provocation effectiveness. The linear correlation and different regressions were calculated to determine these relations. Moreover, the seismic energy reduction in the rock mass was evaluated by means of SRMS Index, which is a factor measured directly before and after blasting. The analyses covered one mine panel in the Polkowice-Sieroszowice copper mine over four-year period.
\end{abstract}

Keywords: copper ore deposit, underground mining, induced tremors, rock burst, group winning blasting

\section{Introduction}

Underground copper ore mining in Poland is associated with the Legnica-Głogów Copper District (LGCD) located in the south-western part of the country, where in 1957 the copper ore deposit was discovered and KGHM Polish Copper JSC has been operating since 1961. The company consists of three mines Rudna, Lubin, Polkowice-Sieroszowice and three copper smelters Cedynia, Głogów, Legnica [1].

Factors such as exploitation under constrained conditions at great depth in a single seam deposit, sandstone zones without copper mineralization, the use of room-and-pillar mining

\footnotetext{
${ }^{*}$ Corresponding author: anna.gogolewska@pwr.edu.pl
} 
systems not rarely leaving remnants, cause a rock burst hazard, which is the most dangerous threat in the mines. This hazard also results from the geological structure and tectonics of the deposit [2].

In the LGCD mines, rock burst prevention must be used as an inseparable element of mining technology. Long-term, temporary and organizational preventive methods have been developed. The temporary methods include, but are not limited to, group excavation and face blasting, which consists in firing simultaneously several or a dozen or more faces (possible maximum number) in order to provoke tremors or rock bursts while waiting after blasting and thus induce elastic energy reduction in rock mass. The key preventive measure is monitoring the condition of the rock mass and the effectiveness of rock burst prevention by means of convergence measurements, continuous recording of seismic activity (mining seismology), passive seismic tomography as well as geotechnical and geological observations. In addition, observations of seismoacoustic activity induced by group blasting are carried out with the use of the Microprocessor Meter of Crackles (MMC) before and after blasting works, whose results are presented as the Synthetic Index of Rock Mass Stability (SRMS Index) [3].

To-date, the group blasting has been the most important active method for reducing rock burst hazard, hence the aim of the study was to assess its effectiveness in inducing seismic events and to determine its relationship with rock mass seismicity and blasting parameters. The necessity of evaluating the condition of the rock mass is governed by state legal regulations as well as internal mine ordinances. The analyses covered the D-IE block, which belongs to the D field in the G-54 division in the Polkowice-Sieroszowice mining plant. Four years (2009-2012) of high seismic activity were selected. For the study purpose the group blasting parameters, seismic activity and rock burst hazard were characterised and investigated. The relationship between the SRMS Index and seismic energy was analysed but only for two years (2009 and 2010), in which the majority of blasting operations were done at regular intervals and seismic hazard was higher compared to 2011-2012 years. Similarly, the correlation between the number of blasted faces, the number of group blasting works and the time length between these operations and the provocation effectiveness related to the number and energy of tremors was analysed for those two years due to the same reasons.

\section{Research area}

The first operational works in the Polkowice mine were conducted in 1968. The Sieroszowice mine was established in 1978 as a result of drilling new excavations from the Rudna and Polkowice mines and crossing the boundaries of the Sieroszowice mining area with these excavations. The new mine did not have its own shaft, therefore the Rudna mine's shaft was used to transport the ore to the surface $[1,4]$.

The existing Polkowice-Sieroszowice mine plant, was created in 1996 by merging the Polkowice mine with the Sieroszowice one $[1,5]$. The mine is mining in the following mining areas: Sieroszowice (in $85 \%$ of this area, because its $15 \%$ is exploited by the Rudna mine), Polkowice, Radwanice-East (Radwanice-Wschód), and in the part of the Deep Industrial Głogów (Głogów Głęboki-Przemysłowy-GGP) (in 50\% of this area, because 50\% of the area will be mined by the Rudna mine) (Fig. 1).

The mine operates in 20 mining fields at a depth of 600 to $1200 \mathrm{~m}$, and the GGP plant will exploit the deposit at a depth of over $1200 \mathrm{~m}$. The copper ore exploitation conditions are good in most of the area occupied by the mine. Difficulties may occur only in the southern part of the deposit because of strongly developed tectonics [1].

The mine excavates two lithological types of copper ore i.e. sandstone and carbonateslate ores. The thickness of the deposit is relatively small and depends on the part being exploited; in the Polkowice area it is in the range of 0.6 to $4.5 \mathrm{~m}$, with the average thickness 
of $2.5 \mathrm{~m}$; in the area of Sieroszowice it varies from 0.7 to $4.5 \mathrm{~m}$, and the average thickness reaches $2.0 \mathrm{~m}$. Due to the thin layers the mine does not use hydraulic backfill but roof selfdeflection to protect and liquidate the empty post mining space. The bolting system is used to support the roof and walls of excavations $[3,4,5]$.

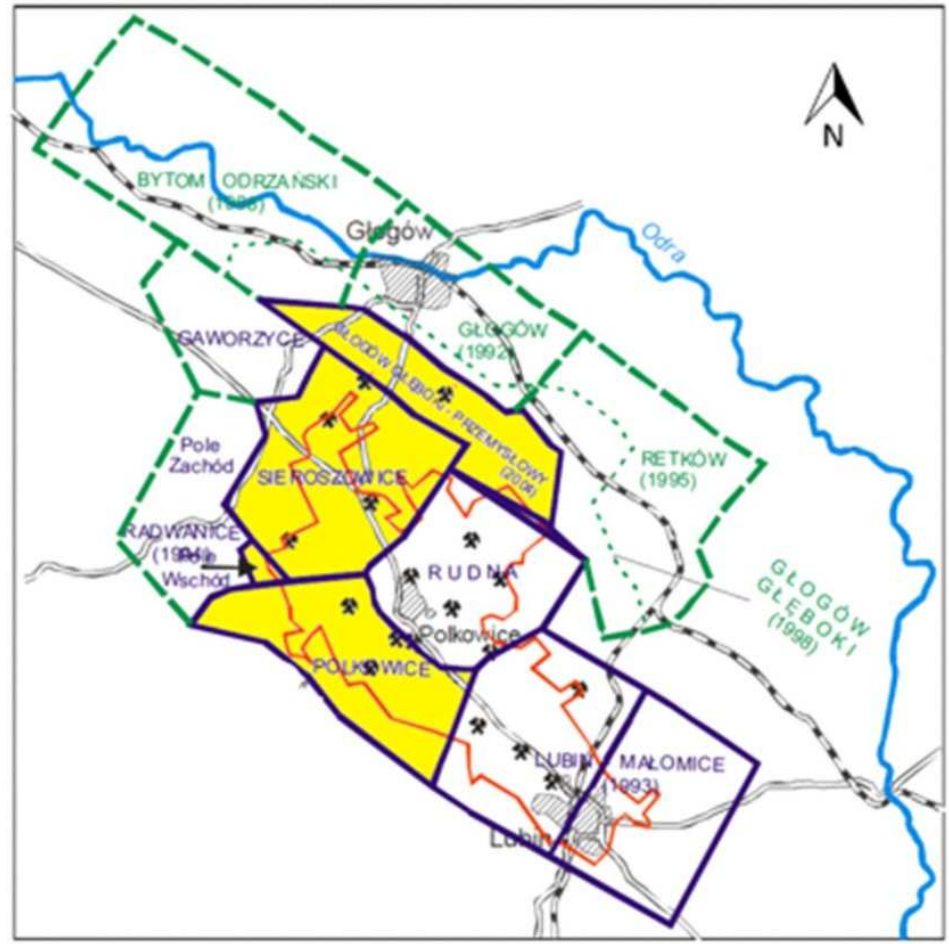

Fig.1. Mining areas of the Polkowice-Sieroszowice copper ore mine (marked in yellow)

(Sieroszowice, Polkowice, Radwanice-Wschód (Radwanice-East) and Głogów Głęboki-Przemysłowy (Deep Industrial Głogów) (based on [5]).

The exploitation is carried out with various types of a one-stage room-and-pillar system with roof self-deflection, which are adapted to the geological and mining conditions. The deposit is excavated with the use of a blasting technique. Mining and transport are carried out with machines adjusted to a small deposit thickness. The one-stage room-and-pillar system with roof self-deflection (J-UG-PS- the acronym in Polish) is used in four mining divisions of the Polkowice-Sieroszowice mine including the G-54 one $[3,4,5]$.

The G-54 division belongs to the mining area of Sieroszowice. the D field lies at a depth of 925 to $1050 \mathrm{~m}$ and consists of the D1E floor, D2E floor, D3E floor and D-IE block. The $\mathrm{D}$ field is bounded on the northern side with inclines, from the south and east it borders with the Rudna mine, while on the western side it is limited by a drift and a zone without mineralization located within the D1E floor (Fig. 1).

\section{Results and discussion}

Analysis of the provocation effectiveness of blasting works covered the D-IE block in the G54 division in 2009-2012 years. To determine the appropriate mine field and years for the research, seismic activity was calculated. The effectiveness of seismic energy reduction in rock mass with the use of the group blasting was calculated and assessed taking account of 
tremors and their effects in form of rock bursts. The parameters of the blasting works were determined, including their number, number of faces to be blasted and the time between successive blasting works. The variability of the SRMS Index in relation to seismic activity was observed. The correlation between blasting work parameters and the effectiveness of the inducement of tremors and rock bursts was calculated.

\subsection{Seismic activity}

Seismic activity in the G-54 division and in the D-IE block in years 2009-2012 was high. It was described by the number and energy of tremors and rock bursts. It has been assumed that tremors are seismic phenomena with $\mathrm{E} \geq 1 \cdot 10^{3} \mathrm{~J}$ energy while high-energy tremors have $\mathrm{E} \geq 1 \cdot 10^{5} \mathrm{~J}$ energy. The seismic activity is shown in Table 1 and Figure 2. In 2009-2012 years, in the G-54 division 948 tremors with total energy of $5.53 \cdot 10^{8} \mathrm{~J}\left(5.84 \cdot 10^{5} \mathrm{~J} / 1\right.$ tremor $)$ occurred including 129 high-energy ones with total energy of $5.42 \cdot 10^{8} \mathrm{~J}\left(4.20 \cdot 10^{6} \mathrm{~J} / 1\right.$ tremor).

In the D-IE block there were 644 tremors with total energy of $4.42 \cdot 10^{8} \mathrm{~J}$ $\left(6.86 \cdot 10^{5} \mathrm{~J} / 1\right.$ tremor $)$, including 88 high-energy ones with total energy $4.34 \cdot 10^{8} \mathrm{~J}\left(4.93 \cdot 10^{6} \mathrm{~J} / 1\right.$ tremor). The majority of tremors (250) occurred in 2011, in 2009 the least (95) were registered. In 2010 there were 147 seismic events and in 2012, 152 ones. In 2010, the energy of tremors was the highest and amounted to $2.55 \cdot 10^{8} \mathrm{~J}$ and in 2009 it reached $8.15 \cdot 10^{7} \mathrm{~J}$. The total energy of tremors was the smallest $\left(1.02 \cdot 10^{7} \mathrm{~J}\right)$ in 2012 . The largest amount of energy per 1 tremor was $1.74 \cdot 10^{6} \mathrm{~J} / 1$ tremor in 2010 and the lowest in $2012\left(6.74 \cdot 10^{4} \mathrm{~J} / 1\right.$ tremor).

In the D-IE block, the majority (29) of high-energy tremors occurred in 2009, in 2010 only one less tremor was recorded (28) (Figure 2). In 2010, the total energy of high-energy tremors was the highest and amounted to $2.54 \cdot 10^{8} \mathrm{~J}$ and in 2009 it reached $8.04 \cdot 10^{7} \mathrm{~J}$. In 2011 there were 18 high-energy tremors with total energy of $9.19 \cdot 10^{7} \mathrm{~J}$. The smallest number (13) and energy $\left(7.98 \cdot 10^{6} \mathrm{~J}\right)$ of tremors appeared in 2012 . This year, there was no tremors of energy equal to or larger than $1 \cdot 10^{7} \mathrm{~J}$. The largest energy per one high-energy tremor $\left(9.07 \cdot 10^{6} \mathrm{~J}\right)$ was in 2010 .

It can be stated that the energy of tremors decreased in subsequent years of 2009-2012 period, which means that the seismic risk was reduced. The seismic activity in the G-54 division was determined by that of the D-IE block, so the analyses were focused on this block. The years 2009-2011 were more active compared to 2012 year, which justified the selection of 2009-2011 period to be assessed in further investigations.

At the beginning of October 2012, the progress of all the faces of the rooms directed to the block border was stopped by the stony zone. Thus, the development of the exploitation front of the D-IE block was completed; only liquidation of workings was carried out. In October, November and December no tremors were provoked.

\subsubsection{Rock bursts in G-54 mining division over 2009-2012 period}

In the Polkowice-Sieroszowice mine within the years 2009-2012, there were 22 rock bursts with a total energy of $1.11 \cdot 10^{9} \mathrm{~J} ; 11$ of them with a total energy of $4.21 \cdot 10^{8} \mathrm{~J}$ occurred in the G-54 division, including 8 ones with energy of $3.43 \cdot 10^{8} \mathrm{~J}$ occurred in the D-IE block. In 2009 , there were 9 rock bursts in the entire mine $\left(1.7 \cdot 10^{8} \mathrm{~J}\right)$, in the G-54 division 3 rock bursts $\left(6.41 \cdot 10^{7} \mathrm{~J}\right)$ and $2\left(4.8 \cdot 10^{7} \mathrm{~J}\right)$ occurred in the D-IE block. In 2010 , there were 9 rock bursts in the entire mine $\left(8.09 \cdot 10^{8} \mathrm{~J}\right)$, in the G-54 division there were 5 events $\left(2.44 \cdot 10^{8} \mathrm{~J}\right)$ and 4 ones occurred in the D-IE block $\left(2.13 \cdot 10^{8} \mathrm{~J}\right)$. In 2011 , the number and energy of rock bursts dropped significantly. There were 4 rock bursts in the whole mine $\left(1.35 \cdot 10^{8} \mathrm{~J}\right)$, in the G-54 division 3 events $\left(1.13 \cdot 10^{8} \mathrm{~J}\right)$ appeared, 2 in the D-IE block $\left(0.82 \cdot 10^{8} \mathrm{~J}\right)$. In 2012 , there were no rock bursts in the mine, which could be related to the completion of the cutting in the DIE block. It can be noticed that the number and energy of rock bursts increased in 2010 
compared to 2009 and then considerably decreased during the period 2011 to 2012 . The rock burst hazard in the entire mine was primarily affected by that of D-IE block.

Table 1. Seismic activity in G-54 mining division and D-IE block related to energy classes in years 2009-2012.

\begin{tabular}{|c|c|c|c|c|c|c|c|c|}
\hline \multirow[b]{2}{*}{ Year } & \multicolumn{5}{|c|}{ Energy Class $[\mathbf{J}]$} & \multirow{2}{*}{$\begin{array}{l}\text { Number } \\
\text { of } \\
\text { Tremors }\end{array}$} & \multirow{2}{*}{$\begin{array}{c}\text { Total } \\
\text { Energy } \\
{[\mathbf{J}]}\end{array}$} & \multirow{2}{*}{$\begin{array}{c}\text { Energy } \\
\text { per one } \\
\text { Tremor } \\
{[\mathrm{J}]} \\
\end{array}$} \\
\hline & $10^{3}$ & $10^{4}$ & $10^{5}$ & $10^{6}$ & $10^{7}$ & & & \\
\hline \multicolumn{9}{|c|}{ G-54 mining division } \\
\hline 2009 & 46 & 36 & 27 & 3 & 3 & 115 & $9.87 \cdot 10^{7}$ & $8.58 \cdot 10^{5}$ \\
\hline 2010 & 104 & 59 & 26 & 7 & 6 & 202 & $2.93 \cdot 10^{8}$ & $1.45 \cdot 10^{6}$ \\
\hline 2011 & 209 & 96 & 17 & 6 & 3 & 31 & $1.33 \cdot 10^{8}$ & $4.02 \cdot 10^{5}$ \\
\hline 2012 & 174 & 95 & 25 & 6 & 0 & 300 & $2.84 \cdot 10^{7}$ & $9.46 \cdot 10^{4}$ \\
\hline $\begin{array}{c}\text { Number of } \\
\text { Tremors }\end{array}$ & 533 & 286 & 95 & 22 & 12 & 948 & $5.53 \cdot 10^{8}$ & $5.84 \cdot 10^{5}$ \\
\hline \multicolumn{9}{|c|}{ D-IE block } \\
\hline 2009 & 41 & 25 & 24 & 3 & 2 & 95 & $8.15 \cdot 10^{7}$ & $8.58 \cdot 10^{5}$ \\
\hline 2010 & 81 & 38 & 18 & 5 & 5 & 147 & $2.55 \cdot 10^{8}$ & $1.74 \cdot 10^{6}$ \\
\hline 2011 & 156 & 76 & 13 & 3 & 2 & 250 & $9.50 \cdot 10^{7}$ & $3.80 \cdot 10^{5}$ \\
\hline 2012 & 78 & 61 & 11 & 2 & 0 & 15 & $1.02 \cdot 10^{7}$ & $6.74 \cdot 10^{4}$ \\
\hline $\begin{array}{c}\text { Number of } \\
\text { Tremors }\end{array}$ & 356 & 200 & 66 & 13 & 9 & 644 & $4.42 \cdot 10^{8}$ & $6.86 \cdot 10^{5}$ \\
\hline
\end{tabular}

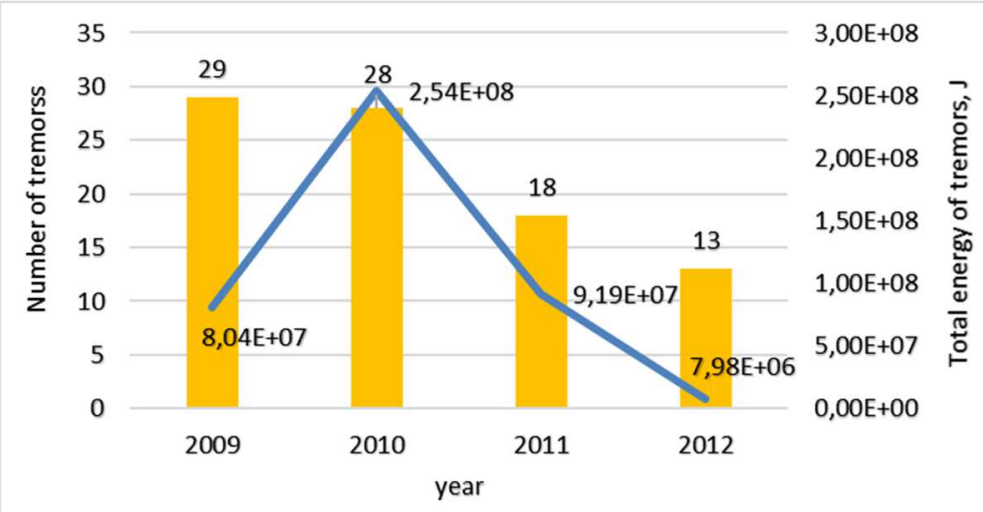

Number of high-energy tremors $\longrightarrow$ Total energy of high-energy tremors

Fig.2. Number and total energy of high-energy tremors in D-IE block in years 2009-2012.

\subsection{Group winning blasting parameters}

In rock bursting prevention active methods are widely used to reduce threats triggered by rock bursts. They are based on special blasting works carried out not only in the solid face, but sometimes also in the floor and roof. Blasting works are performed in the excavations to mine the ore; in roof layers to trigger a roof to collapse and to eliminate the mined-out space; at the floor of workings and walls of the pillars, to reduce the rock mass seismicity. Provoking the rock mass to vibrate with group blasting works proved to be a very effective method reducing the rock burst threat used in Polish copper ore mines $[3,4,6]$. The winning group blasting works were characterized by their frequency, which was defined and calculated by the time length between subsequent blasting operation (in hours), the number of blasting 
works within one month, the number of faces blasted simultaneously, the number of faces blasted in a month in the D-IE block. The group blasting parameters were analysed over 2009-2012 years. During the first three years of the period (2009-2011) a relatively significant number of regular blasting works were performed compared to 2012 year. Therefore, majority of further analyses were referred to 2009-2011 years.

The number of blasting works during each year is presented in Table 2. In 2009 the number of blasting works was 218, in 2010 it was 217, in 2011 decreased to 137 and in 2012 decreased to 77 . During 2009-2012 period 649 blasting works were done. In 2009, the monthly average number of blasting works was 18.2 , in 2010 it slightly decreased to 18.1 , in 2011 it decreased to 11.4 and in 2012 it was only 8.6.

Table 2. Monthly average number of group blasting works in D-IE block in years 2009-2012.

\begin{tabular}{|c|c|c|}
\hline Year & $\begin{array}{c}\text { Number of Blasting } \\
\text { Works }\end{array}$ & $\begin{array}{c}\text { Monthly Number of } \\
\text { Blasting Works per year }\end{array}$ \\
\hline 2009 & 218 & 18.2 \\
\hline 2010 & 217 & 18.1 \\
\hline 2011 & 137 & 11.4 \\
\hline 2012 & 77 & 8.6 \\
\hline
\end{tabular}

Table 3 includes the number of faces blasted in particular months in each year. In year 2012 from October to December no blasting works were done, which was connected with decreasing area of exploitation and difficult mining and geological conditions. So, nine months (January to September) of 2012 year should be considered in the further calculations. In 2009, 3,124 faces were blasted, and in 2010, 3,450 ones. The monthly number of faces per one blasting in 2009 was 14.3 and in 2010 it reached 15.9. Monthly number of faces varied from 89 to 397 and was relatively stable. In 2011, 2,666 faces were blasted, and in 2012, 1,369 ones. The monthly number of faces per one blasting in 2011 increased to 19.5 and in 2012 to 17.8 compared to 2009-2010 years. Monthly number of faces varied from 10 to 397 and was relatively unstable.

During 2009-2012 period the monthly average time between blasting works varied from $22 \mathrm{~h}$ to $624 \mathrm{~h}$ and was relatively stable excluding that in 2012 year (Table 4.) The average monthly time interval between subsequent blasting works in year 2009 was $32.1 \mathrm{~h}$, in 2010 it slightly decreased to $30.2 \mathrm{~h}$, in 2011 it significantly increased to $61.3 \mathrm{~h}$ and in 2012 it enlarged to $150.8 \mathrm{~h}$. Therefore, in 2009 the faces of headings were blasted every 32.1 hours, in 2010 they were blasted slightly more frequently i.e. every 30.2 hours, in 2011 the blasting operations were performed every 61.3 hours and in 2012 they were carried out every 150.8 hours. The time between successive blasting works significantly increased in 2011 and 2012 compared to the 2009-2010 years.

The results of observations done in 2012 year are not well comparable with results obtained in years 2009-2011 since in 2012 the exploitation was constrained due to difficult mining and geological conditions (occurrence of vast stone zones); excavation was stopped at the beginning of October. The necessity to increase the number of faces in 2011 and 2012 might be connected with decreasing number of blasting works due to the aforementioned conditions and still high seismic hazard. 
Table 3. Number of faces blasted in D-IE block in a given month in years 2009 and 2010.

\begin{tabular}{|c|c|c|c|c|c|c|c|c|c|c|c|c|c|c|}
\hline Month & I & II & III & IV & $\mathrm{V}$ & VI & VII & VIII & IX & $\mathrm{X}$ & XI & XII & \begin{tabular}{|c} 
Total \\
Number \\
of \\
Faces
\end{tabular} & $\begin{array}{c}\text { Faces } \\
\text { in one } \\
\text { blasting }\end{array}$ \\
\hline Year & \multicolumn{14}{|c|}{2009} \\
\hline $\begin{array}{l}\text { Number } \\
\text { of Faces }\end{array}$ & 265 & 259 & 224 & 158 & 247 & 325 & 145 & 250 & 338 & 360 & 265 & 288 & 3,124 & 14.3 \\
\hline Year & \multicolumn{14}{|c|}{2010} \\
\hline $\begin{array}{l}\text { Number } \\
\text { of Faces }\end{array}$ & 279 & 303 & 320 & 312 & 186 & 340 & 384 & 397 & 387 & 89 & 265 & 188 & 3,450 & 15.9 \\
\hline Year & \multicolumn{14}{|c|}{2011} \\
\hline $\begin{array}{l}\text { Number } \\
\text { of Faces }\end{array}$ & 209 & 115 & 269 & 171 & 193 & 316 & 269 & 260 & 257 & 261 & 192 & 154 & 2,666 & 19.5 \\
\hline Year & \multicolumn{14}{|c|}{2012} \\
\hline $\begin{array}{l}\text { Number } \\
\text { of Faces }\end{array}$ & 280 & 261 & 218 & 135 & 94 & 153 & 10 & 128 & 90 & 0 & 0 & 0 & 1,369 & 17.8 \\
\hline
\end{tabular}

Table 4. Monthly average time between subsequent blast works in a given month in D-IE block in years 2009-2010.

\begin{tabular}{|c|c|c|c|c|c|c|c|c|c|c|c|c|c|}
\hline Month & I & II & III & IV & V & VI & VII & VIII & IX & X & XI & XII & per one year \\
\hline Year & \multicolumn{10}{|c|}{$\mathbf{1 0 0 9}$} \\
\hline Time [h] & 27 & 29 & 32 & 27 & 30 & 29 & 55 & 35 & 32 & 28 & 30 & 32 & 32.1 \\
\hline Year & \multicolumn{10}{|c|}{} & \multicolumn{10}{|c|}{$\mathbf{2 0 1 0}$} \\
\hline Time [h] & 30 & 33 & 29 & 31 & 29 & 29 & 24 & 22 & 29 & 24 & 32 & 52 & 30.2 \\
\hline Year & \multicolumn{10}{|c|}{$\mathbf{1 0 1 1}$} \\
\hline Time [h] & 63 & 55 & 56 & 75 & 54 & 54 & 56 & 56 & 61 & 58 & 59 & 89 & 61.3 \\
\hline Year & \multicolumn{10}{|c|}{$\mathbf{1 0 1 2}$} \\
\hline Time [h] & 67 & 62 & 67 & 95 & 150 & 102 & 624 & 96 & 94 & - & - & - & 150.8 \\
\hline
\end{tabular}

\subsection{Effectiveness of group winning blasting in provocation of rock bursts and tremors}

The assessment of the effectiveness of provoking seismic dynamic events by the group blasting works consists in determining the percentage of the number and energy of provoked events in the number and energy of all the recorded seismic phenomena. The group blasting works are the more effective, the higher the percentage of the number and the energy of the provoked seismic events is. The effectiveness of provocation related to energy is the most crucial factor because the release of cumulated energy in the rock mass reduces seismic hazard to a large extent. The effectiveness was assessed for the D-IE block and 2009-2012 years. The analysis covered rock bursts, tremors with energy of $\mathrm{E} \geq 10^{3} \mathrm{~J}$ and those with energy of $\mathrm{E} \geq 10^{5} \mathrm{~J}$ (i.e. high-energy tremors) (Table 5).

In years $2009-2012$, in the entire mine, 15 rock bursts of $9.44 \cdot 10^{8} \mathrm{~J}$ of total energy were provoked by blasting, which indicated $68 \%$ efficiency related to the number of rock bursts and $85 \%$ efficiency related to the energy of tremors causing the rock bursts. In the G-54 division blasting works provoked $8\left(3.16 \cdot 10^{8} \mathrm{~J}\right)$, which posed $72.7 \%$ effectiveness for the number and $75.1 \%$ for energy. In the D-IE block $7\left(2.86 \cdot 10^{8} \mathrm{~J}\right)$ rock bursts were provoked, which indicated $87.5 \%$ effectiveness for their number and $83.4 \%$ for energy.

In 2009, in the entire mine, the effectiveness of provoking rock bursts related to their number reached 44\% and that for energy, 58.8\%. In the G-54 division and the D-IE block, the effectiveness of rock bursts' provocation for their number was $66.7 \%$ and $100 \%$ 
respectively while that for energy amounted to $75 \%$ and $100 \%$ respectively. In 2010 , in the whole mine, the provocation effectiveness of rock bursts related to their number was $77,8 \%$ and that related to energy reached $91.5 \%$. In the G-54 division, the effectiveness of rock bursts' provocation for their number was $80 \%$ and that for energy reached $76.2 \%$. In the DIE block, the effectiveness for rock bursts' number was $75 \%$ and for energy reached $73,2 \%$. In 2011, in the entire mine, the effectiveness of provoking the rock bursts related to their number and energy reached $75 \%$ and $77 \%$ respectively. In the G-54 division, the effectiveness for rock bursts' number was $66.7 \%$ and that for energy reached $72.3 \%$. In the D-IE block the effectiveness for both their number and energy amounted to $100 \%$. In 2012 no rock bursts appeared. It can be stated that the provocation of rock bursts by group blasting works was highly effective.

In 2009, in D-IE block, the effectiveness of tremors' provocation in relation to their number was $17.9 \%$ and to their energy reached $84.4 \%$. The effectiveness for high-energy tremors amounted to $17.2 \%$ for their number and $85.3 \%$ for their energy. In 2010 , the provocation effectiveness for tremors' number was $21.1 \%$ and for their energy it amounted to $71.9 \%$. The provocation effectiveness for high-energy tremors was $21.4 \%$ for number and $72.2 \%$ for energy. In 2011 , the effectiveness of tremors' provocation in relation to their number was $20.4 \%$ and in relation to their energy it was $87.9 \%$. The effectiveness for highenergy tremors was $27.8 \%$ for their number and $89.7 \%$ for their energy. In 2012 , within first nine months, the effectiveness of tremors' provocation for their number was $38.2 \%$ and for their energy it was $16.9 \%$ while such effectiveness for high-energy tremors was $30.8 \%$ for their number and $7.8 \%$ for energy.

It can be noticed that in 2010 the effectiveness of provocation of tremors for their energy decreased and for their number increased compared to 2009 while in 2011 the effectiveness connected with number of tremors slightly dropped but energy provocation effectiveness increased largely compared to 2010 . The provocation effectiveness associated with energy played the most decisive role in seismic hazard reduction. During 2009-2011 years in the DIE block, such effectiveness was very high and the group blasting works fulfilled their aim completely. However, in 2012, the efficiency for energy decreased largely to $7.8 \%$ due to stopping the excavation; only liquidation operations were carried out.

Table 5. Effectiveness of blasting related to number and energy of tremors in D-IE block.

\begin{tabular}{|c|c|c|c|c|}
\hline \multirow[b]{2}{*}{ Year } & \multicolumn{2}{|c|}{ Tremors of Energy of $E \geq 10^{3} \mathrm{~J}$} & \multicolumn{2}{|c|}{ Tremors of Energy of $E \geq 10^{5} \mathrm{~J}$} \\
\hline & $\begin{array}{c}\text { Effectiveness } \\
\text { related to } \\
\text { Number of } \\
\text { Tremors } \\
\end{array}$ & $\begin{array}{c}\text { Effectiveness } \\
\text { related to } \\
\text { Energy of } \\
\text { Tremors } \\
\end{array}$ & $\begin{array}{c}\text { Effectiveness } \\
\text { related to } \\
\text { Number of } \\
\text { Tremors } \\
\end{array}$ & $\begin{array}{c}\text { Effectiveness } \\
\text { related to } \\
\text { Energy of } \\
\text { Tremors } \\
\end{array}$ \\
\hline$[-]$ & {$[\%]$} & {$[\%]$} & {$[\%]$} & {$[\%]$} \\
\hline 2009 & 17.9 & 84.4 & 17.2 & 85.3 \\
\hline 2010 & 21.1 & 71.9 & 21.4 & 72.2 \\
\hline 2011 & 20.4 & 87.9 & 27.8 & 89.7 \\
\hline 2012 & 38.2 & 16.9 & 30.8 & 7.8 \\
\hline
\end{tabular}

\subsection{SRMS Index and seismic energy}

The measurement of seismoacoustic activity induced with blasting works is used to assess the stress concentration in rock mass after blasting operations in KGHM mines.

The Microprocessor Meter of Crackles (MMC) records seismoacoustic activity occurring in the region of its installation site (up to approx. $50 \mathrm{~m}$ ) before and after blasting operations and calculates the SRMS Index, which can vary from 1 to 10 class. The higher the value of the Index, the greater stress concentration in the rock mass. Any increase in the SRMS Index 
is treated as a growing disturbance of the rock balance due to an increase in stress concentration.

A significant rise of the Index, by 3 or more classes, may indicate an increased probability of a strong dynamic event occurrence. Moreover, a decrease in the number and energy of crackles may mean that the stress concentration zone is moving away, while the increase of these parameters may suggest approaching the region with enhanced stress concentration.

The SRMS Index was analysed in the D-IE block over the period of 2009-2011 years since the majority of seismoacoustic observations were then carried out and a large number of blasting works were regularly done. 996 measurements of the SRMS Index were performed (in 2009-380, in 2010-354, in 2011-262). In 2009, three significant growth of the SRMS Index were recorded; they took place in March, April and August. In March, the seismic activity was low, only three seismic tremors occurred, while in April there was a rock burst and in August the energy of tremors was significant. Thus, the increase in the Index properly indicated the destabilization of the rock mass twice. In July, there was a rock burst but the Index was stable and low. In 2010, there were six large growths in the Index, but only in December this growth was connected with a rock burst. In April, October and December, rock bursts occurred but the SRMS Index remained low and stable. In 2011, there were six large growths in the SRMS Index, but only in December the increase was connected with the rock burst. In years 2009-2011, fifteen significant growths of the Index were found and three of them were associated with rock bursts. The remaining five $(63 \%)$ rock bursts were not accompanied by the substantial growth of the Index. It can be noticed that the stress concentration in the rock mass depicted by the SRMS Index was loosely connected with seismic and rock burst threat. The lack of signalling high-energy tremors with a clear increase in seismoacoustic activity recorded with the Microprocessor Meter of Crackles (MMC) may indicate another mechanism for provoking these tremors.

\subsection{Effectiveness of provocation of seismic events in relation to parameters of group blasting works}

The relationships between the effectiveness of the group blasting in the provocation of tremors and the number of blasting works, the time length between the subsequent blasting works and the number of blasted faces were determined. For this purpose, Pearson linear correlation coefficients and linear and polynomial regressions were calculated. The analysis was carried out for the D-IE block for high-energy tremors and for tremors of $\mathrm{E} \geq 1 \cdot 10^{3} \mathrm{~J}$ energy. The period 2009-2011 was selected for the analyses since the large number of regular blasting works and seismoacoustic observations were then performed.

No clear relationship was found between the effectiveness of tremor provocation and the number of blasting works and the number of blasted faces. The linear correlation coefficient between the number of blasting works and effectiveness was -0.13 (number of tremors) and -0.2 (energy of tremors). The correlation coefficient between the number of faces and the effectiveness was -0.1 (tremors' number) and -0.14 (energy).

The linear relationship between the effectiveness of tremor provocation and the length of time between successive blasting operations (frequency) was only found. The correlation coefficient of 0.48 (effectiveness related to number of tremors) and of 0.47 (effectiveness related to energy of tremors) were obtained for high-energy tremors. The correlation coefficient of 0.47 (effectiveness related to number of tremors) and of 0.50 (effectiveness related to energy of tremors) were obtained in case of tremors of $\mathrm{E} \geq 1 \cdot 10^{3} \mathrm{~J}$ energy. It can be said that the longer the time passed between successive blasting works, the greater their effectiveness in the provocation of tremors was. When the frequency of blasting was lower, the energy of provoked tremors was higher. 


\section{Conclusions}

1. The seismic activity in the D-IE block over 2009-2012 years remained at a high level, which justified the application of the group blasting to reduce seismic and rock burst hazard. The total number and energy of rock bursts and tremors decreased in subsequent years, which may be connected with the high effectiveness of group blasting in provoking tremors and rock bursts.

2. The obtained results confirmed that the group blasting was the highly effective way of decreasing the seismic hazard in the D-IE block.

3. The seismoacoustic SRMS Index was not clearly related with the seismic activity and the associated rock burst threat in the D-IE block in 2009-2011; the lack of indicating high-energy tremors by means of an explicit growth of seismoacoustic activity might suggest other mechanism for generating these tremors. This would be an interesting issue for future research.

4. In 2009-2011 in the D-IE block both the number and energy effectiveness of provocation of seismic events did not depend on the number of group blasting works or blasted faces. However, they were inversely proportional to the frequency of blasting; the energy of induced tremors increased with decreasing intensity of blasting works. Future investigations are necessary to further develop and confirm these initial findings by analysis conducted in diverse geological and mining conditions and over extended time period.

5. The results indicate the necessity to assess the provocation effectiveness of blasting so that the seismic hazard could be controlled to a certain extent.

The paper publishing was supported by the statutory research 0401/0125/17/21.

\section{References}

1. P. Kijewski (ed.), Monografia, Zakłady Górnicze Polkowice-Sieroszowice (Monography Polkowice-Sieroszowice Mining Plant), KGHM Cuprum Sp. z o.o., Wrocław (2006) (in Polish)

2. W. Konopko, Wieloźródłowość wstrzasów górotworu (Multi-origin of induced tremors), Przegląd Górniczy 65, 72-75 (2009) (in Polish)

3. J. Butra, Eksploatacja złoża rud miedzi w warunkach zagrożenia tapaniami i zawałami (Exploitation of the copper ore deposit under conditions of rock bursts and roof falls) KGHM Cuprum Sp. z o.o., Wrocław (2010) (in Polish)

4. A. Piestrzyński (ed.), Monografia KGHM Polska Miedź S.A. (Monography of KGHM Polish Copper JSC), KGHM Cuprum Sp. z o.o., Wrocław (2007) (in Polish)

5. S. Bartlett, H. Burgess, B. Damjanović, R. Gowans, C. Lattanzi, Raport techniczny dotyczacy produkcji miedzi i srebra przez KGHM Polska Miedź S.A. w LegnickoGłogowskim Okręgu Miedziowym w poludniowo-zachodniej Polsce, (Technical report on the production of copper and silver by KGHM Polish Copper JSC in the LegnicaGłogów Copper District in south-western Poland), KGHM Polska Miedź S.A., Lubin (2013) (in Polish)

6. Z. Kłeczek, Grupowe strzelanie przodków jako element profilaktyki tapaniowej w kopalniach rud miedzi LGOM (Group blasting as a part of rock burst prevention in LGOM copper mines), Górnictwo i Geoinżynieria 28, 153-159 (2004) (in Polish) 